\title{
Research Paper \\ The Effectiveness of Nerve Planning Group-Languages Cognitive Expectancy and Quality of Life for Children With Cancer
}

\author{
Sanaz Aghakhani ${ }^{1}{ }^{(0},{ }^{*}$ Farshad Bahari ${ }^{2,3}[0$
}

1. MA, Department of Psychology, Khomein Branch, Islamic Azad University, Khomein, Iran.

2. PhD in Counseling, Assistant Professor, Department of Psychology, Khomein Branch, Islamic Azad University, Khomein, Iran

3- Head of Department of Student Health Education and Monitoring, Ministry of Health and Medical Education, Tehran, Iran.

\begin{tabular}{|c|c|}
\hline $\begin{array}{l}\text { Use your device to scan } \\
\text { and read the article online }\end{array}$ & Citation Aghakhan S, Bahari F. [The Effectiveness of Nerve Planning Group-Languages Cognitive Expectancy and Quality \\
\hline 口ing & $\begin{array}{l}\text { of Life for Children With Cancer (Persian)]. Iranian Journal of Psychiatry and Clinical Psychology. 2018; 24(3):256-269. http:// } \\
\text { dx.doi.org/10.32598/ijpcp.24.3.256 }\end{array}$ \\
\hline pristis & dol]": http://dx.doi.org/10.32598/ijpcp.24.3.256 \\
\hline
\end{tabular}

Funding: See Page 267

(c) Copyright: The Author(s)

Received: 08 Jan 2018

Accepted: 12 Jun 2018

Keywords:

Neuro-Linguistic programming, Hope, Quality of Life, Cancer Children

\begin{abstract}
A B S TRACT
Objectives This study aimed to examine the effect of Neuro-Linguistic Programming (NLP) on the hope and quality of life in children with cancer.

Methods The study design is quasi-experimental study with pretest, posttest, follow-up and control group. Study population consisted of children (male and female) with cancer at AminrKabir Hospital and Tabassom Cancer Support Community in 2016 who applied for NLP training and were under treatment. Of these, 40 were selected by random sampling, and assigned to NLP and control groups. The data collection tools were Children's Hope Scale (CHS) and Generic Children's Quality of Life (GCQ) questionnaire. Data analysis was performed using descriptive statistics, multivariate analysis of variance (MANOVA) and dependent t test in SPSS V. 22.

Results Results showed that NLP training had significant effect on the hope and quality of life, and could predict $40 \%$ and $70 \%$ of variance for hope and quality of life in children with cancer, respectively. Conclusion According to the findings of this study, NLP training increased the quality of life and hope in
\end{abstract} children with cancer.

\section{Extended Abstract}

\section{Introduction}

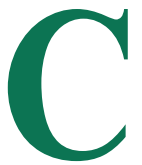

ancer is a rare disease in children and its diagnosis causes significant tension in the families [1]. Children with cancer have graver psychological stress, depression and despair compared to normal children. One of the supportive services that can be provided to patients with cancer is Neuro-Linguistic Programming (NLP). According to Sadukh and Kaplan (2011), depression and psychological stress such as loss of interest, excessive crying, high emotions and energy loss, are seen in disappointed people; interventions seem to be effective in increasing the hope and reducing depression and stress [5]. Harris (1999) argues that NLP helps humans feel more optimistic about their thoughts, feelings and actions to achieve positive outcomes. In NLP, effective communication is of particular importance [7].

Quality of life is a valuable construct that measures one's feelings about his or her health. Quality of life is wellknown for health professionals and one of their main concerns and also an indicator for measuring health status in health-related studies. Access to information about quality

\section{* Corresponding Author:}

Farshad Bahari, PhD

Address: Department of Psychology, Khomein Branch, Islamic Azad University, Khomein, Iran.

Tel: +98 (80) 88363560

E-mail: fbahari200277@yahoo.com 
of life is not only an effective way of treatment and future development, but also an assistance to promotion of rehabilitation programs and interventions [14]. Apparently, there is a lack of information in this area that needs to be researched. In this regard, this study aims to investigate whether NLP training could affect the hope and quality of life in children with cancer.

\section{Methods}

The present study is a quasi-experimental research with pretest, posttest, follow-up and control group. Study population consisted of children (male and female, aged 7-11 years old) with cancer referring to AminrKabir Hospital and Tabassom Cancer Support Community. Of these, 40 were selected by random sampling method, and assigned to control $(n=20)$ and NLP $(n=20)$. At first, a pretest was administered to all of them. The cut-off point for quality of life was considered 104. Then, the NLP group received 8-week NLP training. At the end of the intervention, hope and quality of life of children were assessed again. After one-month, the same tests were administered to the NLP group.

\section{Data collection tools}

For collecting data from participants, Children's Hope Scale (CHS) developed by Snyder (1991) and Generic Children's Quality of Life (GCQ) inventory designed by KidsCape group in 2005 were used [19].

\section{Neuro-linguistic protocol}

The NLP training intervention which is based on theoretical principles and communication techniques, conducted in eight 45-minute sessions twice a week (In fact, it was 10 sessions by considering one meeting before the beginning of intervention and one follow-up meeting at the end of intervention).

\section{Results}

The results of this study showed that NLP training had a significant effect on hope and quality of life of children with cancer. This is consistent with the findings in other studies $[23,24]$. Some studies have suggested that NLP training can improve self-efficacy, anxiety and motivation for success in students [24]. Others have shown that NLP training is effective in motivating students to achieve academic progress. According to the findings of this study and the results of previous studies, NLP group training, based on its basic principles and techniques, affects the relationship of individual with another individual. Using common patterns and tools of NLP and learning hope, cancer patients can discover and model their health status to create effective communication and change attitudes and beliefs of people at different levels. These feelings and thoughts have a direct impact on their health and are real for their bodies. By changing the way they use their feelings, they can change their perceptions and recreate their own world. This helps them to select their health choices. Children with cancer may not be able to change life events, but they can change their response to these events which can reduce their stress and feelings of despair. They use personal skills and perceptions to create and maintain their relationships with others, and use specific goals to create a future that inspires them. The same intervention can be applied to increase the hope and quality of life in children with cancer.

\section{Discussion}

According to the study results, group training of NeuroLinguistic Programming (NLP) has a significant effect on the hope and quality of life in children suffering from cancer. Furthermore, NLP training did not significant affect the self-perception and financial resources. Diagnosis of cancer is usually followed by feelings such as fear, depression, hopelessness, and behaviors like self-questioning, denial, refusal and so on, which can greatly influence the quality of life of the patients with cancer. According to researchers, if children become aware of their misbeliefs, they will be able to change them by using the methods discussed in NLP. Many of the tools used in NLP will help the referrals to reinterpret the problematic elements, organize them and take new approaches. In this regard, the NLP techniques by changing the individuals' beliefs and establishing some skills can have a sustainable effect on the quality of life and hope in children suffering from cancer.

\section{Ethical Considerations}

\section{Compliance with ethical guidelines}

In this research, the form of ethical considerations was filled by the patients and was followed by the therapist.

\section{Funding}

This article is from the MA thesis of Ms. Sanaz Aghakhani in the Department of Psychology, Khomein Branch, Islamic Azad University.

\section{Conflict of interest}

The authors declared no conflict of interest. 


\title{
اثربخشى آموزش تروهى برنامهريزى عصب زبانشناختى بر ميزان اميد و كيفيت زندكى كودكان سرطانى
}

ساناز آقاخانى 'ـ، "فرشاد بهارى"

\author{
ا - كارشناس ارشد، كروه روانشناسى، واحد خمين، دانشعاه آزاد اسلامى، خمين، ايران.

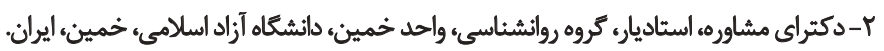

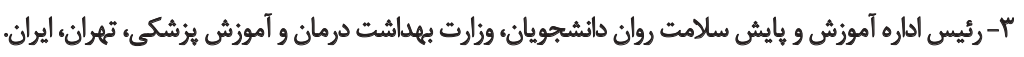

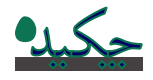

هدأف يروهش حاضر با هدف تعيين ميزان اثربخشى آموزش كروهى برنامهريزى عصب زبانشناختى بر ميزان اميد وكيفيت زندكى كودكان سرطانى ائجام شد.

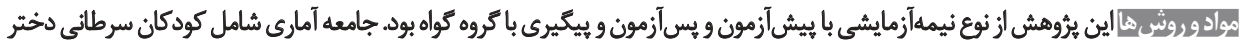

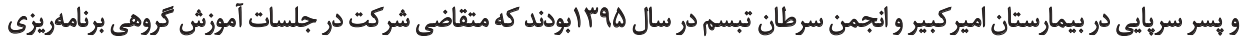

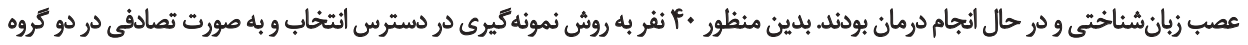

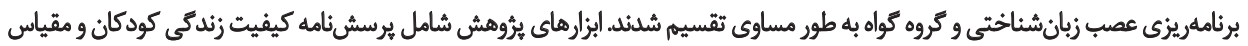

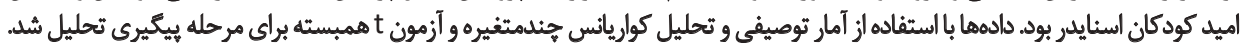

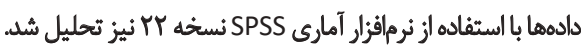

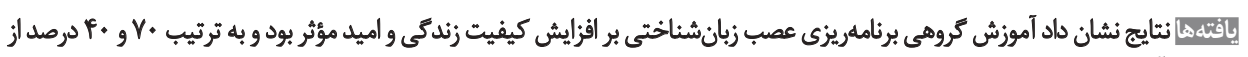

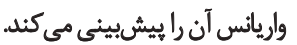

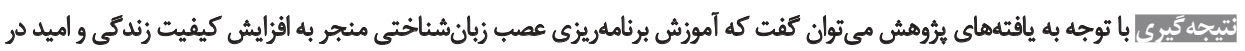
كودكان سرطانى شده است.

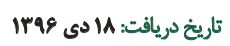

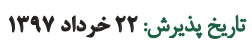

يكى از خدمات حمايتى كه مي توان به كودكان سرطاني ارائه كرد،

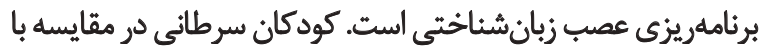

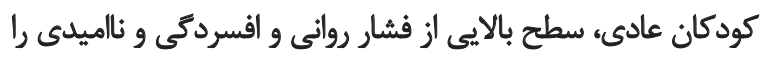

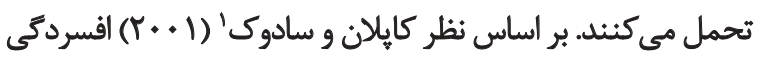

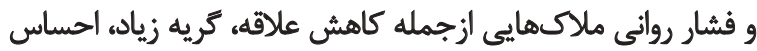

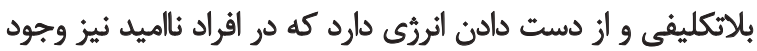

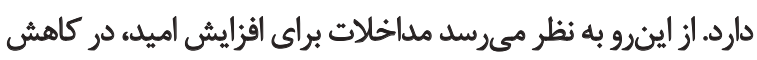

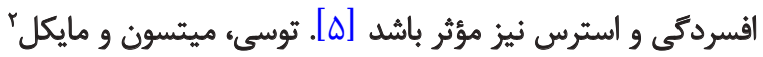

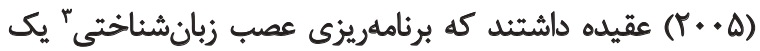

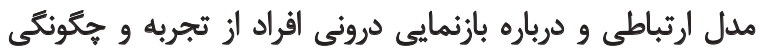

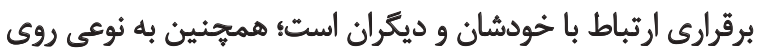

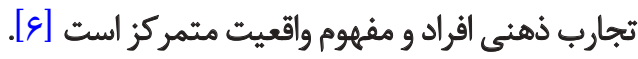

1. Kaplan \& Sadock

2. Tusi, Mytsun \& Michael

3. Neuro-Linguistic Programming (NLP) dalê

سرطان يكى از بيمارىهاى نادر در كودكان است. تشخيص

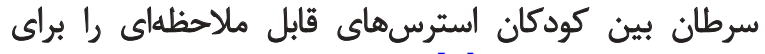

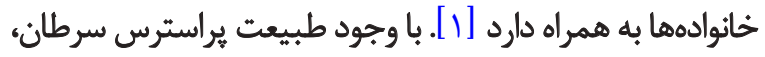

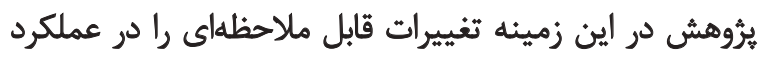

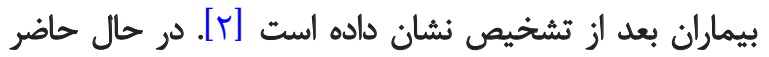

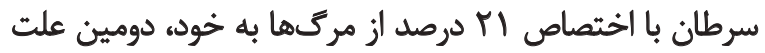

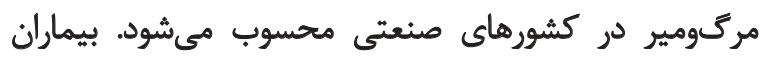

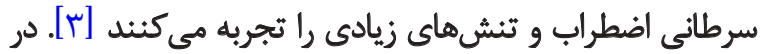

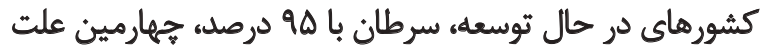

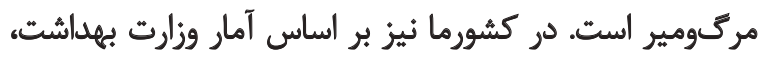

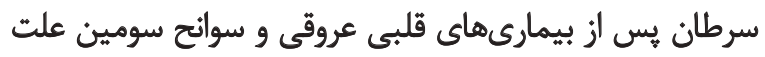

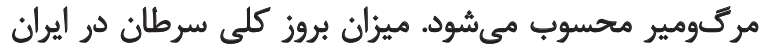

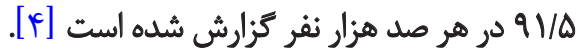


جايكزين درمان افسردمى اسثفاده شود [11]. در يُروهش ديكرى عه دانشآموز بيشدانشكاهى بررسي

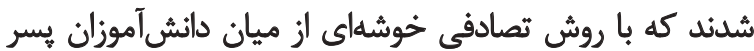

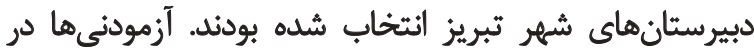

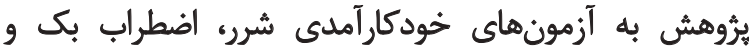

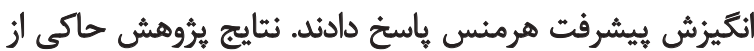

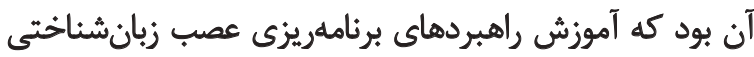

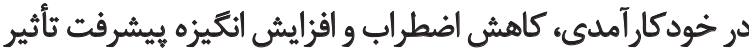

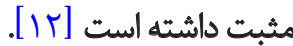

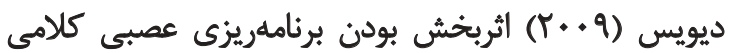

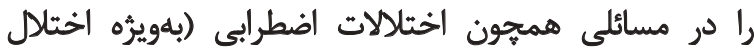

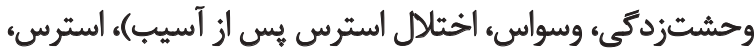

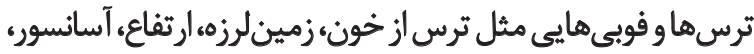

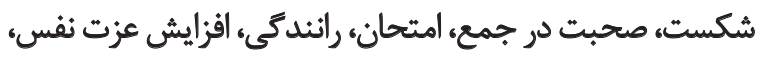

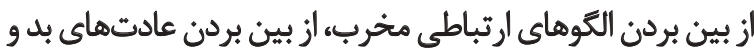

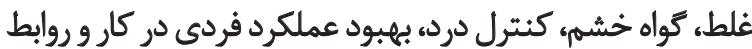

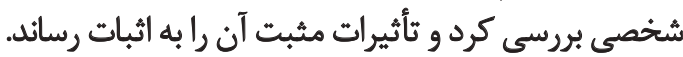

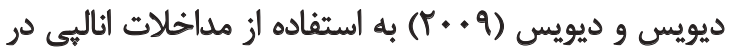

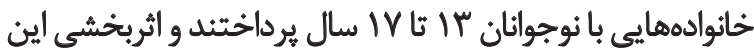

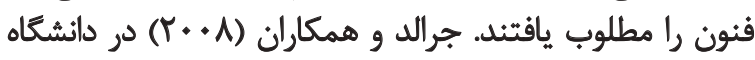

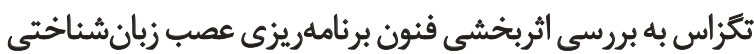

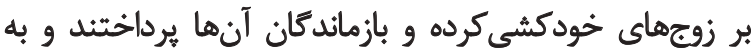
موفقيتهايي در اين زمينه دست يافتيند.

كيفيت زندگى مقوله بيجيديداى است.كيفيت زندگى بهترين

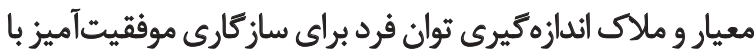

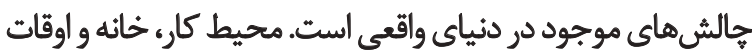

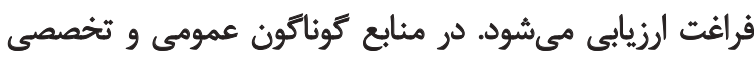

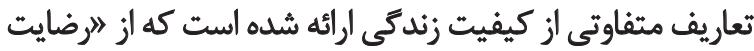

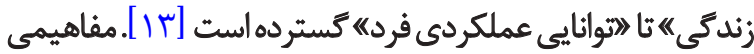

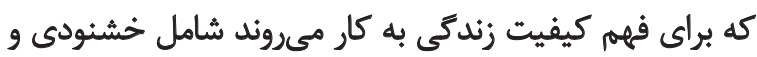

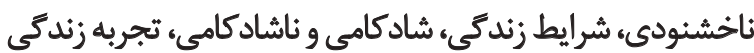

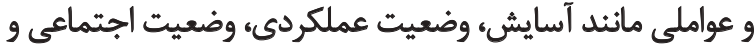

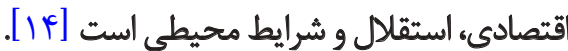

كيفيت زندكى سازه بسيار ارزشمندى است كه احساس فرد

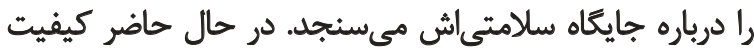

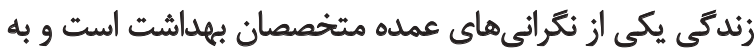

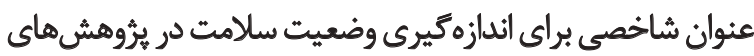

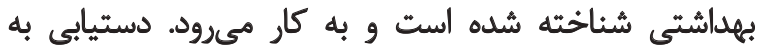

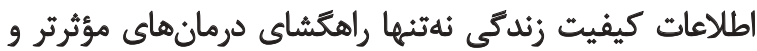

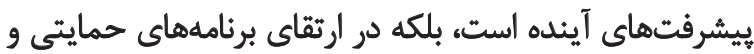

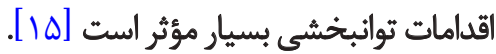

هريس" (1999) توضيح ميىدهد كه برنامهريزى عصب

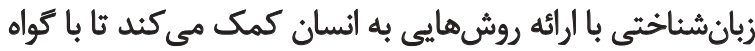

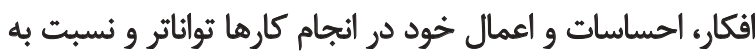

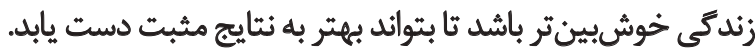

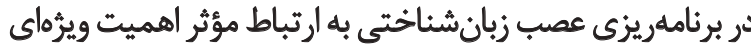

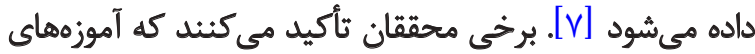

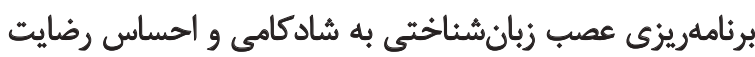
فردى و بينفردى منتهي مي شئود [N]. برناملريزى عصب زبانشناختى برنامهريزى عصب زبانشناختى، فرايند عصبشناختى براى

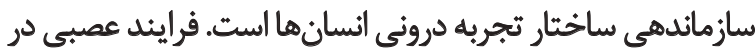

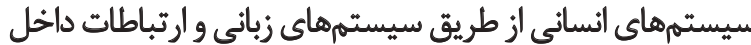

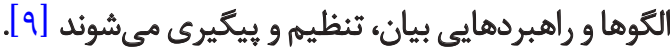

wae

العصاب نقش ويزماى در توليد تخيل و كاركرد ذهن و و روان دارند. در واقع در اين قسمت به جنبه ونهاى عملكرد شناختى ذهن ذهن

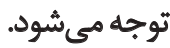

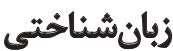

اين قسمت شامل دو بخش مي شود: الـ زبان دوم كه همان قوه

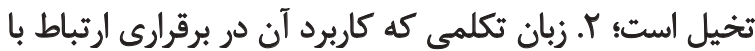

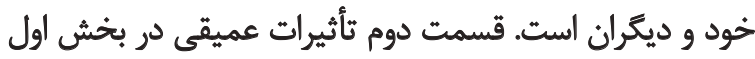

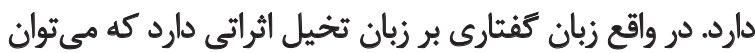
از آن براى برنامهريزى ذهنى استفاده كرد.

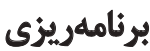

شامل نحوه سازماندهى زبان دوم براى رسيدن به نتايج خاص در

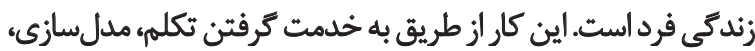

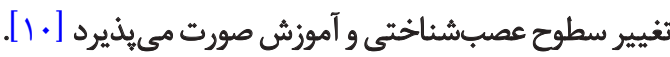
در يروهشى اثربخشى برنامهريزى عصب زبانشناختى و ورئي

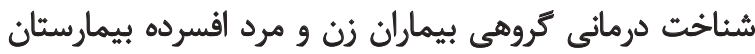

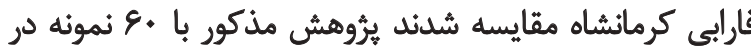

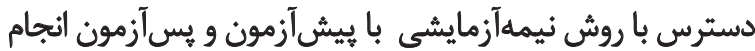

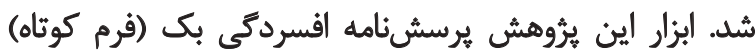

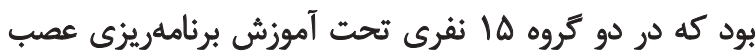

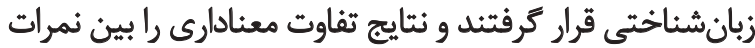

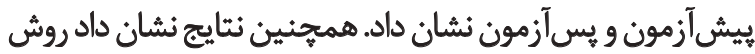

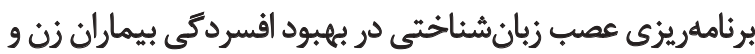

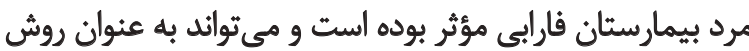




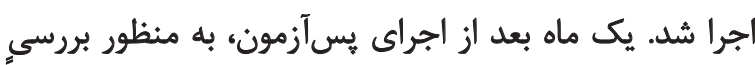

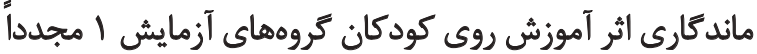

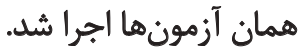

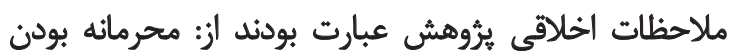

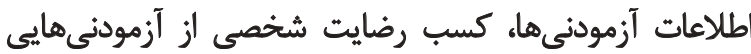

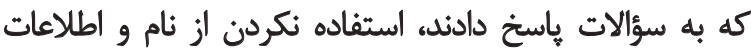

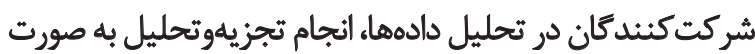

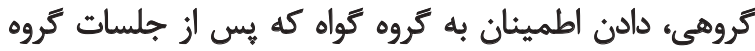

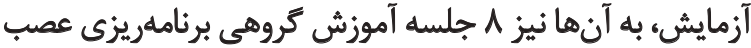

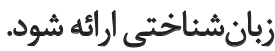

به منظور تجزيهوتحليل دادهها از آماره ميانكَين به عنوان

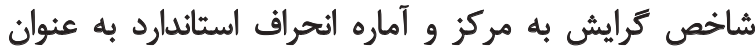

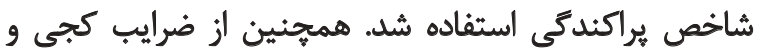

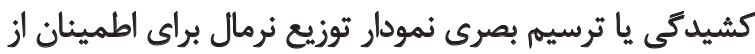

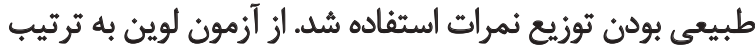

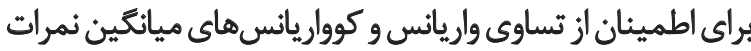

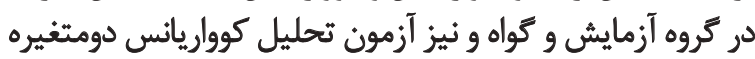

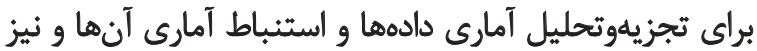

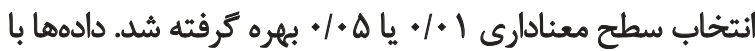

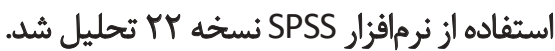

\section{ابئار جمعآورى اطلاعات}

در اين يُروهش ابتدا از روش اسنادى يا كتابخانهاى استفاده

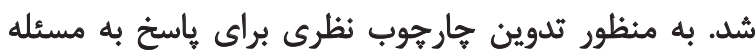

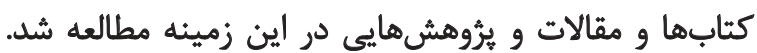

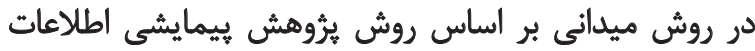

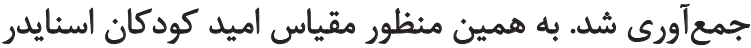

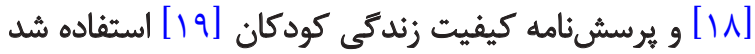

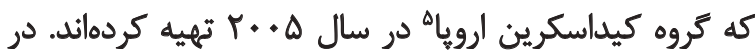

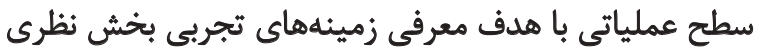

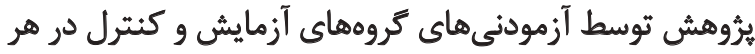

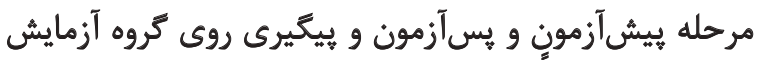

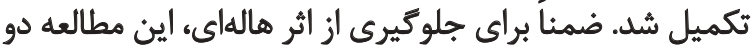

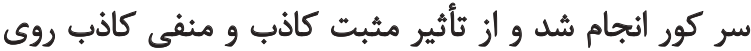

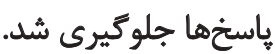

\section{مقياس اميد كودكان در حيطه هاى زندتّى}

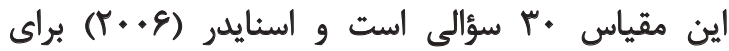

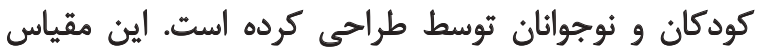

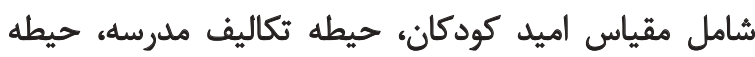

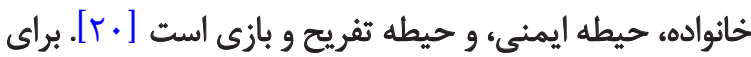

5. The Kidscreen Group Europe
عوامل بسيارى در زندكى باكيفيت مطلوب دخالت دارد. يكى إنى

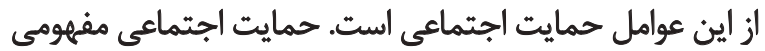

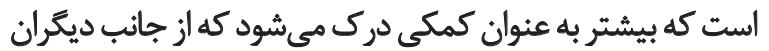

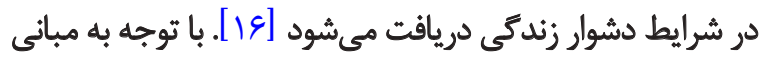

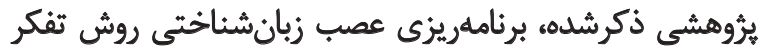

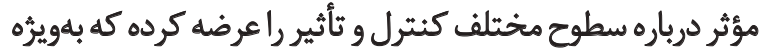

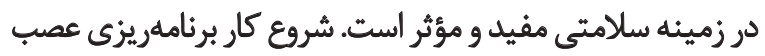

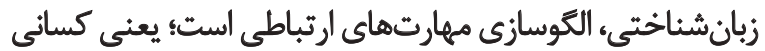

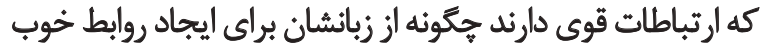

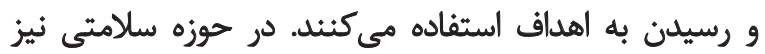

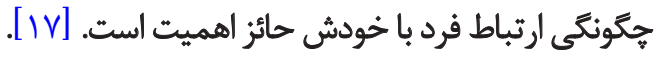
به نظر مىرسد در اين راستا خلأ مطالعائى وجود دارد. بنابراين

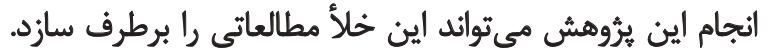

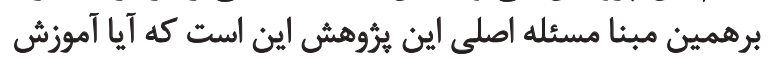

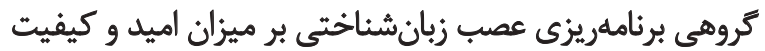
زندكى كودكان سرطانى تأثير معنادار دارد.

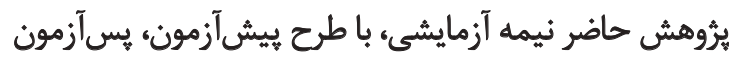

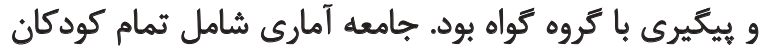

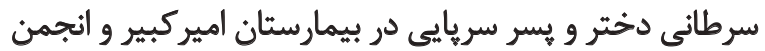

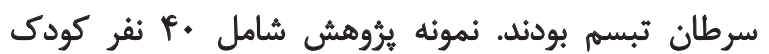

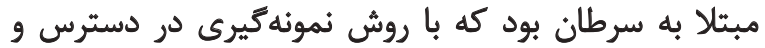

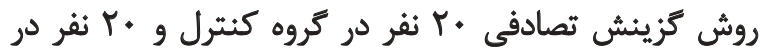

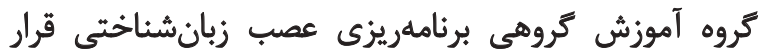

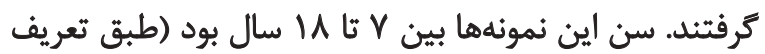

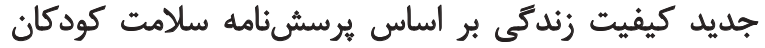

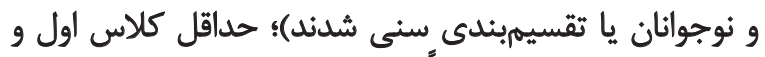

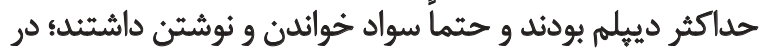
زمان انجام يثوهش در حال انجام درمان بودند

آزمودنىهاى يروهش دو كروه از كودكان سرطانى بودند؛

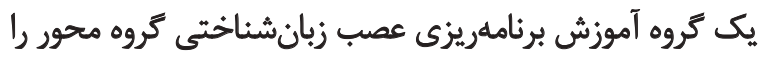

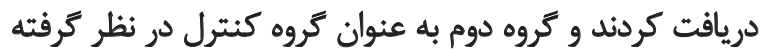

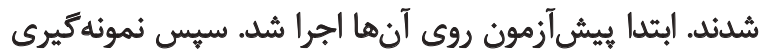

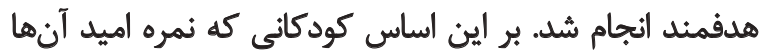

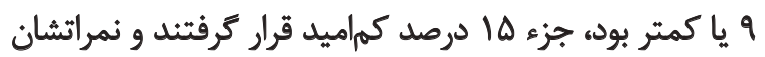

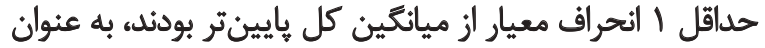

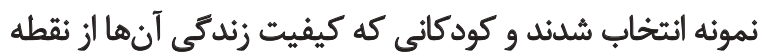

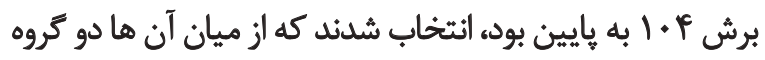
به روش نمونه گيرى تصادفى انتخاب شدند.

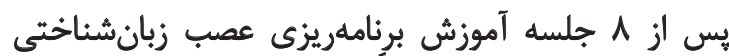

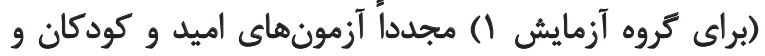
كيفيت زندگى كودكان در جلسه آخر رون روى اعضاى كرونها 


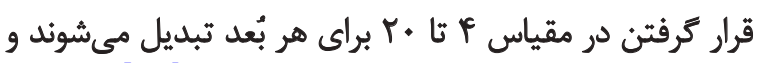

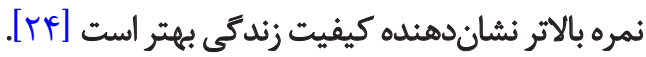
آناليزهايى با ويرُّكىهاى روانكاوى از جنبه مقياس آلفاى

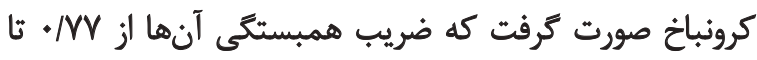

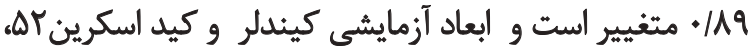

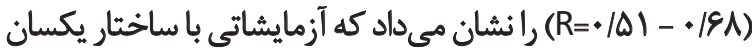

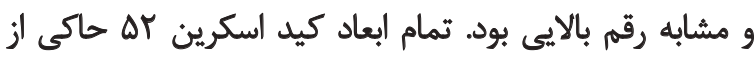

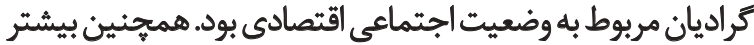
ابعاد آزمايشات حاكى از كراديان عدم سلامت روانى (شى) بود. انسجام درونى ابعاد كيد اسكرين بr با باستفادهاز مقياس آلفاي

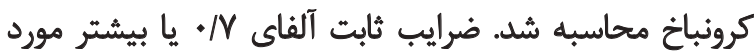

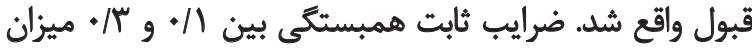

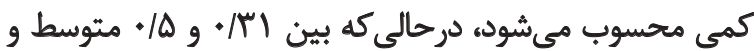

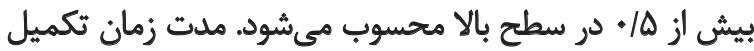

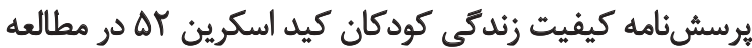

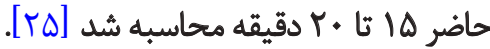

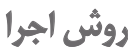

روش اجراى برؤهش به اين صورت بود كه مشاور طى يك

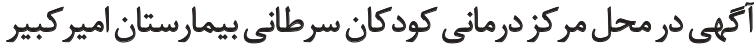

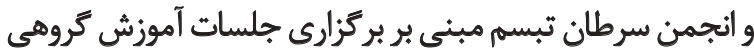

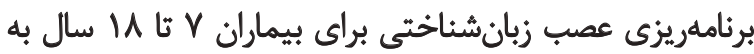

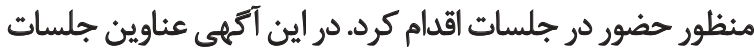

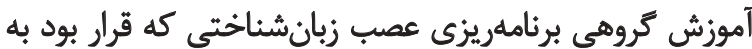

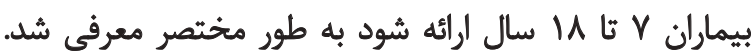

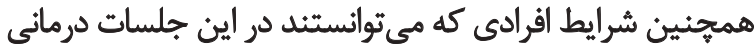

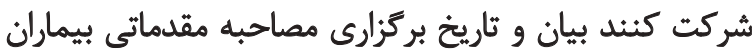

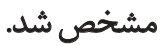
مصاحبهاي كه انجام شد يك مصاحبه نيمهساختيافته بر

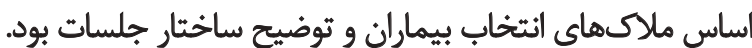

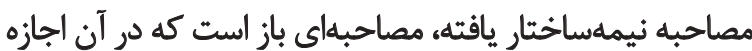

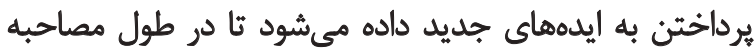

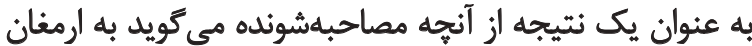

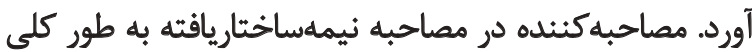

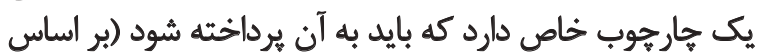

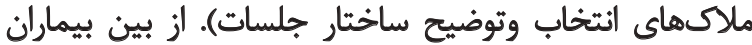

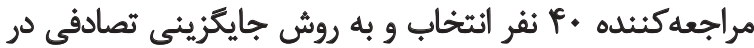

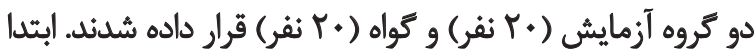

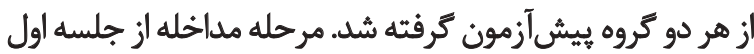

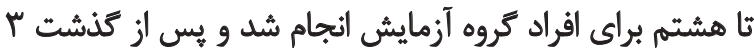

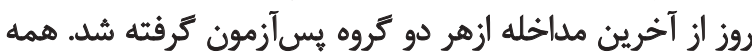
جلسات با حضور درمانكر انجام شد.
ياسخ دادن به سؤالات خردهمقياس اميد كودكان، ييوستارى از

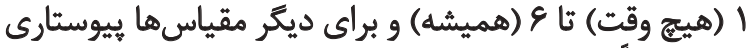

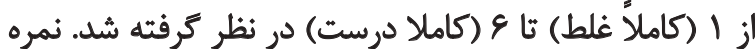

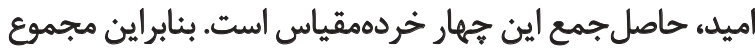

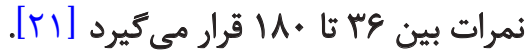
مقياس اميد كودكان يك مقياس شش مادهاى است كه اراده،

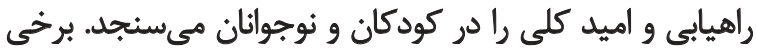

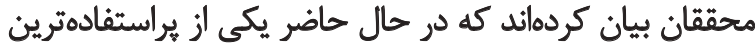

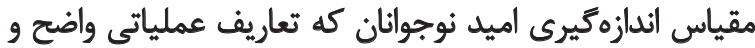

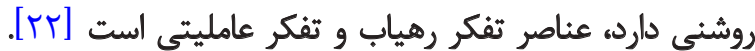

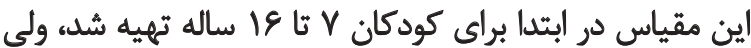

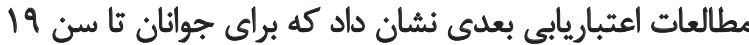

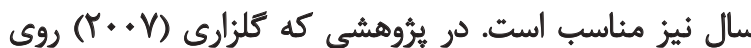

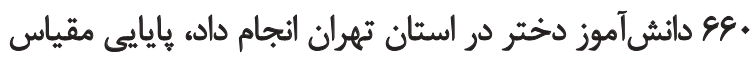

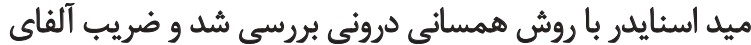

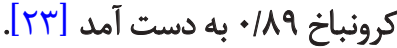

مقياس اميد با مقياسهايى كه فرايندهاى روانشناختى

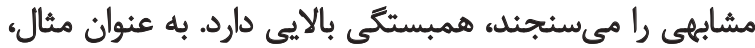

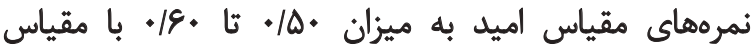

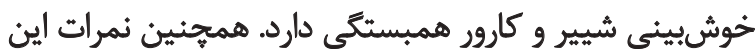

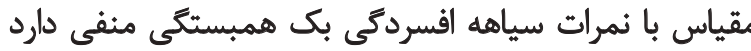

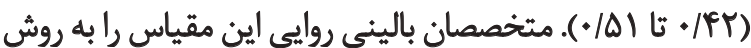

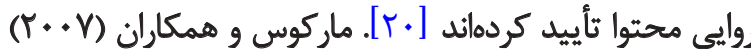

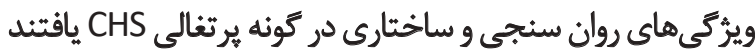

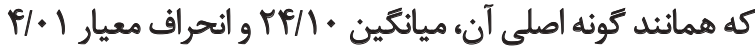

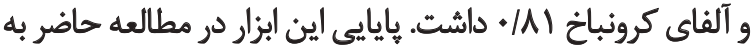

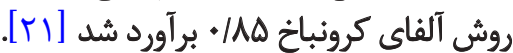

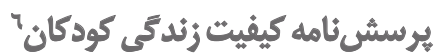

يرسشنامه كيفيت زندگى كودكان و نوجوانان با روش كيد

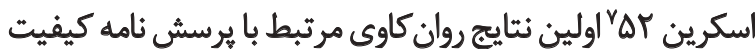

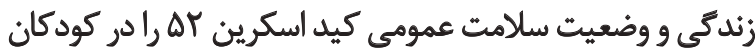

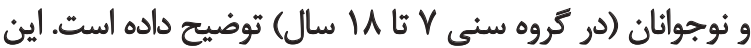

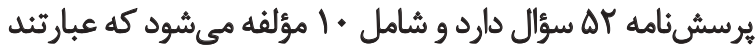

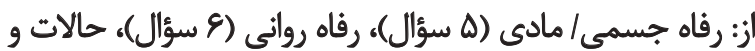

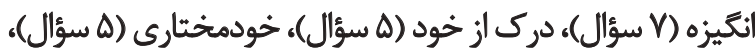

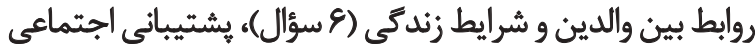

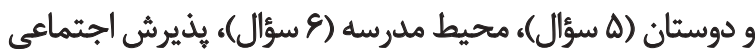

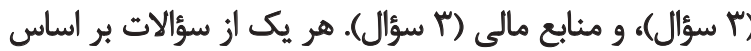

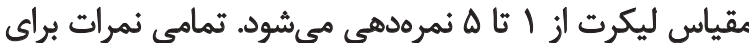

6. World Health Organization (WHO)

7. KIDS CREEN 52 


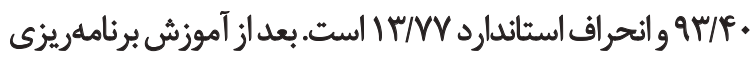

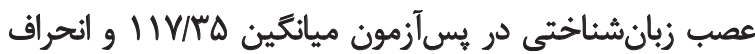

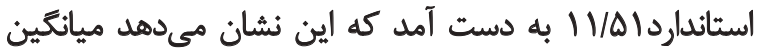

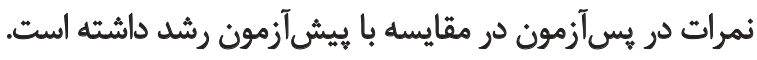

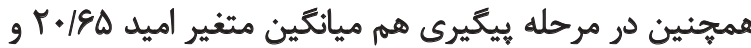

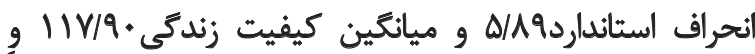

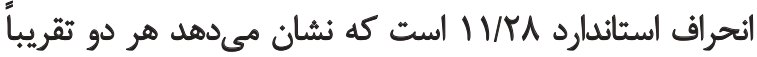

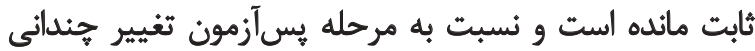
نكرده، ولى در مقايسه با بيش آزمون بسيار تغيير كرده است.

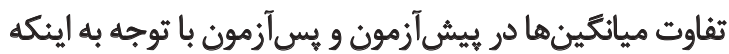

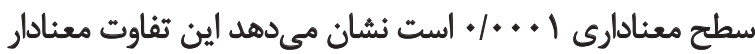

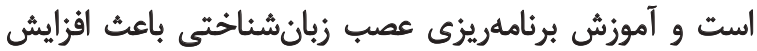

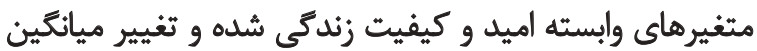
نمرات از بيش آزمون به بس آزمون معنادار است.

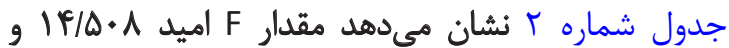

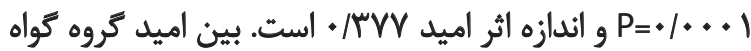

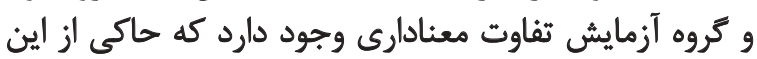

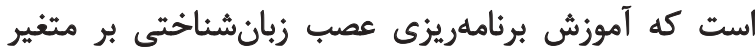

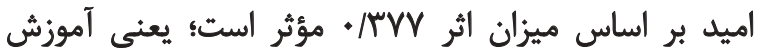

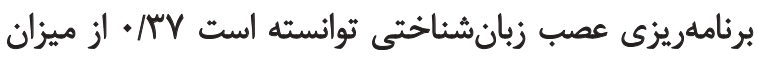

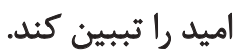

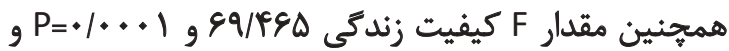

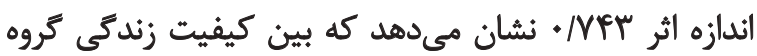

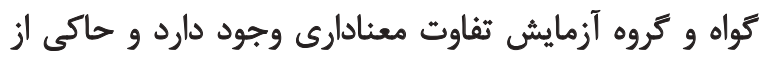

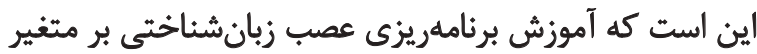

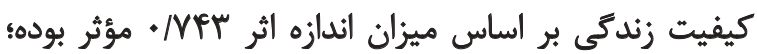

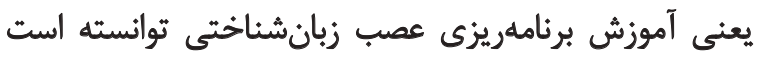

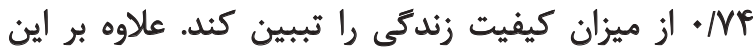

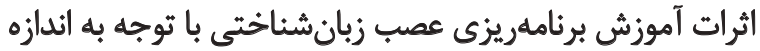

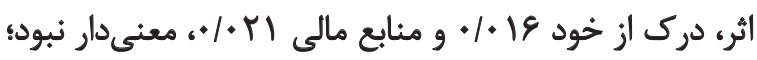

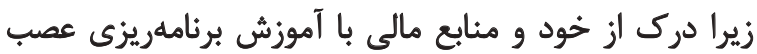

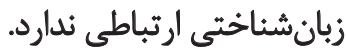

مداخله بر اساس توصيف عملى جلسات اميددرمانى به شيوه

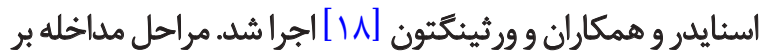

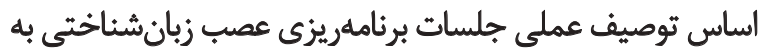

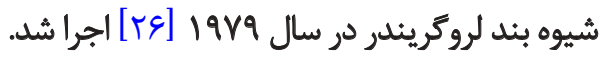

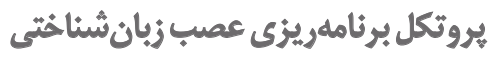

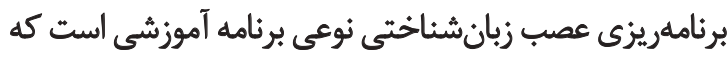

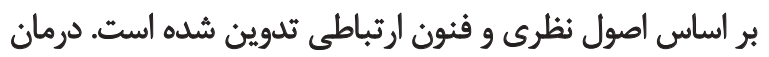

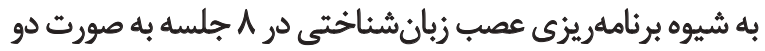

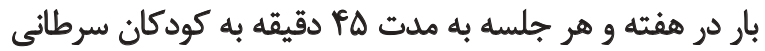

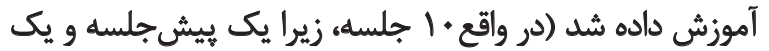
جلسه يُيكيرى نيز بركزار شد).

مباحث جلسات عبارت بودئد از: جلسه اول: شروع آموزشي، بردئ

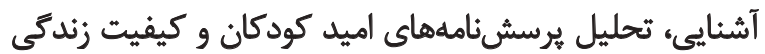

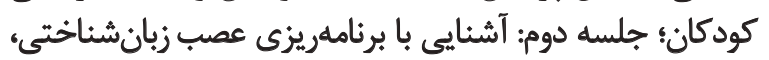

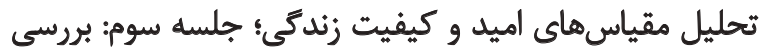

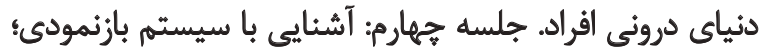

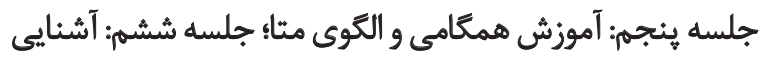

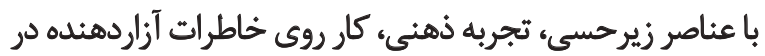

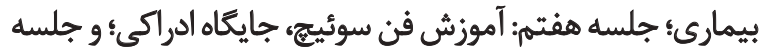
هشتم: تغيير باور، تصوير تازماى از خويشتن.

ياقتهان

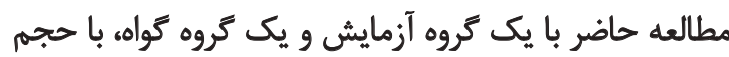

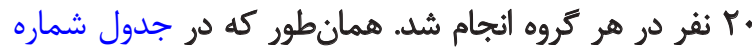

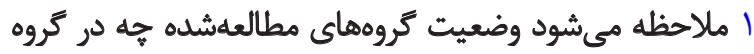

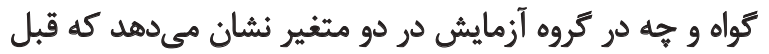

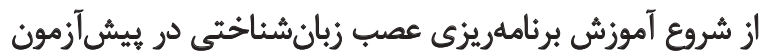

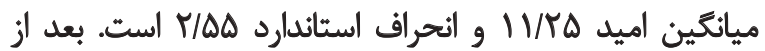

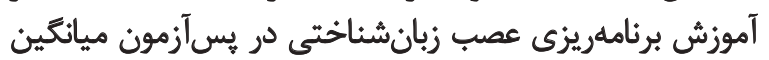

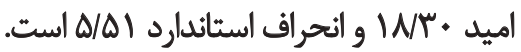
همجنين متغير كيفيت زندكى در بيشآزمون با ميانكين

جدول ا. يافتهاى توصيفى (ميانكين و انحراف استاندارد)

\begin{tabular}{|c|c|c|c|c|}
\hline \multicolumn{3}{|c|}{ ميانكين (انحراف استاندارد) } & \multirow[b]{2}{*}{ ه } & \multirow[b]{2}{*}{ متغير وابِسته } \\
\hline يويكيرى & يسآزمون & يشيشآزمون & & \\
\hline$r \cdot 18 \Delta(\Delta / 19)$ & $W N^{w} \cdot(\Delta / \Delta \mid)$ & $I N / T \Delta(T / \Delta Q)$ & برثامهريزي عصب زبانشئاختى & \multirow{2}{*}{ أميد } \\
\hline- & $1 V / \Lambda \Delta(Y / / 8)$ & $11 / 9 \Delta(T / N 8)$ & olg & \\
\hline $11 V / 9 \cdot(11 / r A)$ & $\| V / r \Delta(11 / \Delta 1)$ & $9 m / f \cdot(1 r / W)$ & برنامهريزي عصب زبانشناختى & \multirow{2}{*}{ كيفيت زندكى } \\
\hline- & $1 \cdot 1 / R+(1 Q / T Y)$ & $1 . . / K^{2} \cdot(1 \Delta / f V)$ & كواه & \\
\hline
\end{tabular}


نتايج حاصل از اجراى آزمون آمارى t همبسته نشان داد بين

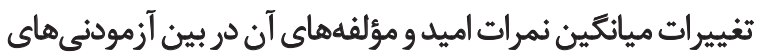

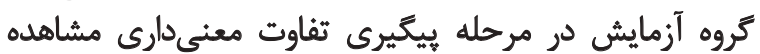

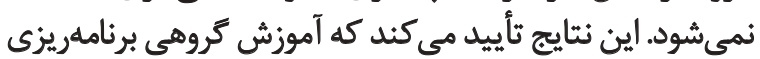
عصب زبانشناختى بر افزايش اميد هايدارى مناسبى دارد.

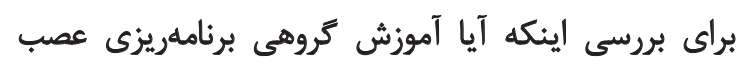

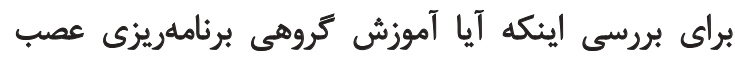

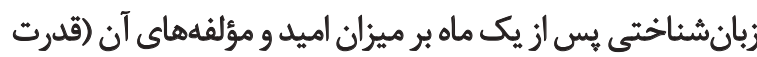

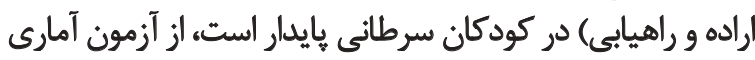

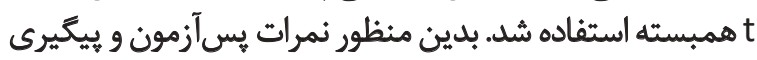

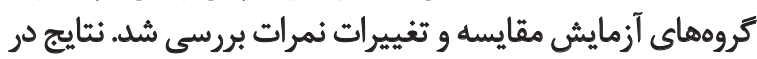
جدول شماره بَ آمده است.

جدول ז. نتايج تحليل كوواريانس اثر برئامهريزى عصب زبانشناختي بر متغيرهاى وابسته

\begin{tabular}{|c|c|c|c|c|c|c|c|c|}
\hline توان أزمون & اندازه اثر & معنى دارى & $\mathbf{F}$ & مجذوراتين & أزادى & مجموع مجذورات & متغير هاي وابستيه & منابع تغييرات \\
\hline $1 / \cdots$ & $\cdot M+H$ & $.1+.1$ & $E q / F E A$ & $r+N \in / \Delta \Delta Y$ & 1 & $r \cdot N / \Delta \Delta V$ & كيفيت زندكى & \multirow{28}{*}{$\begin{array}{l}\overline{2} \\
12 \\
5\end{array}$} \\
\hline $11 \ldots$ & .1818 & $+1+\infty+1$ & "NATAT & $Q N \cdot A V$ & 1 & $W+A V$ & رفاه فيزيكى & \\
\hline $1 / \ldots$ &.$/ 9 V A$ & $.1+\ldots 1$ & $\Delta \cdot / 9 T V$ & $190 / .91$ & 1 & $198 / .91$ & رفاه روائى & \\
\hline.$/ 410$ &.$/ F r y$ & $.1 \ldots+1$ & WEgr & $M I T / \cdot F V$ & 1 & $r I r /+H V$ & احساسات و عواطف & \\
\hline$+1+91$ & $.1 \cdot 18$ & $\cdot|\Delta F|$ & $\cdot / T A F$ & V/Fr. & 1 & $1 / 4 r$ & درى از خود & \\
\hline.$/ M C$ &.$p e q$ & $.1 . . .1$ & WA. Y & AF/ATq & 1 & AF/OYq & خودمختًارى & \\
\hline.$/ 998$ & . /PVA & $.1+\ldots+1$ & TVIFAV & $91 / 15$. & 1 & $91 / 1 \%$. & روابط والدين & \\
\hline . Maff & . MeV & $.1+. .+1$ & $1 r / q \cdot \Delta$ & 181899 & 1 & Ne/899 & حمايت اجتماعى & \\
\hline $11 \ldots$ & . Iate & $+1+.+1$ & $P \cdot / A r$ & $\mid$ |r/FA| & 1 & $|r q / 4 A|$ & هحيط ملرنبه & \\
\hline - AAYA & ./TVA & .10 .9 & $9 / 1 \cdot 1$ & $11 / 481$ & 1 & $11 / 48$ & ليذيرش اجتماعى & \\
\hline$+11 \cdot 0$ & $.1+4$ & - mat & $.10 \cdot 9$ & V/AlP & 1 & l/AlP & منابع مالى & \\
\hline.$/ 9 \Delta \Delta$ &.$/ r W$ & $.1+. .1$ & $1 \varphi / \Delta \cdot \Lambda$ & rep/rnt & 1 & MPE/TYT & اميد & \\
\hline.$/ 9 \Delta$ &.$/ \pi \gamma$ & $+1+\cdots+1$ & $\mid f / \cdot q 4$ & $r q / m r r$ & 1 & Tq/mTr & قلبرث أراده & \\
\hline \multirow[t]{15}{*}{ +laq4 } & (M & $+1++r$ & $W / W$ & $Q \cdot / T \Delta 1$ & 1 & $Q+/ r \Delta 1$ & قدرت راهيابى & \\
\hline & & & & $r . / . r v$ & rf & $r \cdot / 9 .$. & كيفيت زندكى & \\
\hline & & & & $r(\Delta \Delta)$ & re & EI/THI & رفاه فيزيكي & \\
\hline & & & & rMAY & re & QT/TV. & رفاه روائي & \\
\hline & & & & IV/rer & re & rrr/eqI & احساسات و عواطف & \\
\hline & & & & rMt & rf & 19/79) & درى از خُود & \\
\hline & & & & $p / f q e$ & trf & 1.V/A9f & خُودمختارى & \\
\hline & & & & $r / r \cdot r$ & rf & 1../AF. & روابط والدين & \\
\hline & & & & S/THD & rf & $1 F q / g r q$ & حمايت اجتماعى & \\
\hline & & & & r/Trt & rf & $w / r r r$ & محيط مدرسه & \\
\hline & & & & I/TDQ & tif & $r+/ M T r$ & يذيرش اجتماعى & \\
\hline & & & & $r / \Delta S T$ & rf & NA/DFY & مثنابع مالى & \\
\hline & & & & IEIAPT & rf & P.PREV & أهيt & \\
\hline & & & & $r / v q$. & rf & eq/8T & قدرت اراده & \\
\hline & & & & $N \cdot W$ & tre & I9T/AFA & قدرت راهيابي & \\
\hline
\end{tabular}




\begin{tabular}{|c|c|c|c|c|c|c|c|c|}
\hline توان أزمون & اندازه اثر & معثى دارى & $\mathbf{F}$ & مجذيانكين & أزادى & مجموع مجذورات & متغيرهاي وابسته & منابع تغييرات \\
\hline & & & & & $\varphi$. & FAVQAI/... & كيفيت زندكى & \\
\hline & & & & & f. & $\varphi+94 \% \ldots$ & رفاه فيزيكى & \\
\hline & & & & & r. & $N \in \Delta Y / \ldots$ & رفاه روانى & \\
\hline & & & & & r. & $\Delta \Delta \Delta F / \ldots$ & احساسات وعواطف & \\
\hline & & & & & f. & $P Q \cdot V / \ldots$ & درى از خود & \\
\hline & & & & & r. & $\Delta r \cdot r / \ldots$ & خودمختارى & \\
\hline & & & & & f. & $|r \ldots q| \ldots$ & روابط والدين & ฉุ. \\
\hline & & & & & f. & save $\%$ & حمايت اجتماعى & 2 \\
\hline & & & & & r. & $\| W W \ldots$ & محيط هدرسه & \\
\hline & & & & & i. & $r r H / . .$. & يذيرش اجتماعى & \\
\hline & & & & & i. & $r .99 / \ldots$ & منابع مالى & \\
\hline & & & & & p. & 1. TVQ/... & اميد & \\
\hline & & & & & p. & rQ19/... & قدرت أراده & \\
\hline & & & & & p. & $T M q T / \ldots$ & قدرت راهيابيى & \\
\hline
\end{tabular}

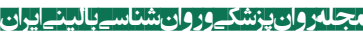

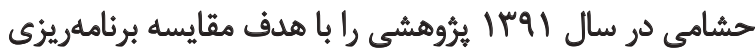

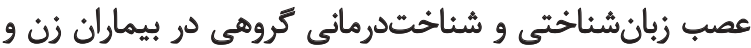

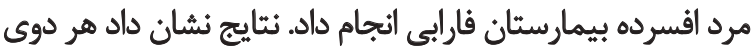

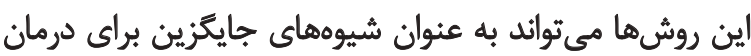

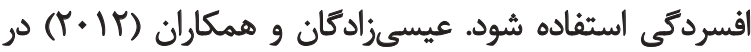

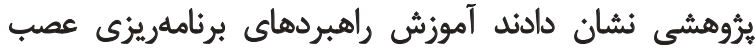

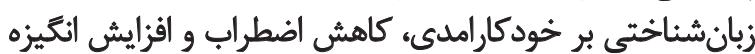
ييشرفت تأثير مثبتى داشته است

نتايج بهدست آمده بانتايج يروهش هائ زير همسو است: ديويس

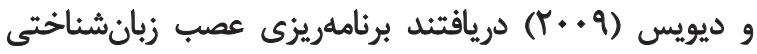

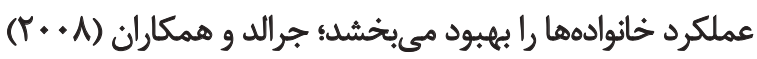

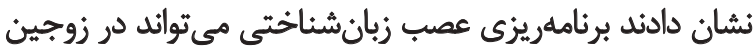

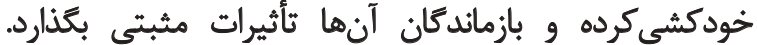

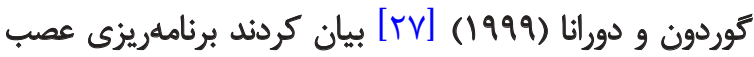

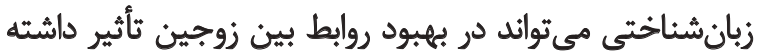

زبانشناختى يس از يك ماه بر ميزان كيفيت زندكى و مؤلفهانهاى

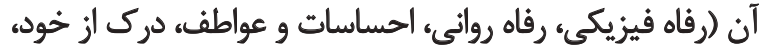

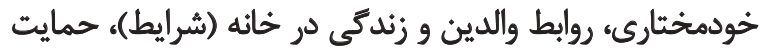

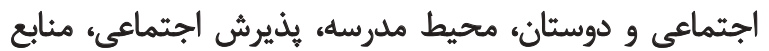

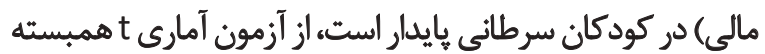

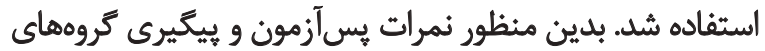

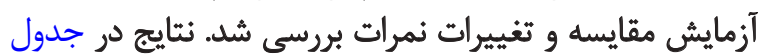
شماره F آمده است.

نتايج حاصل از اجراى آزمون آمارى t همبسته نشان داد

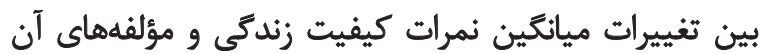

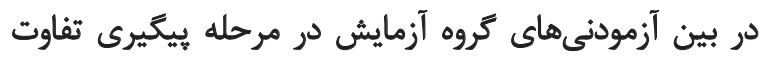

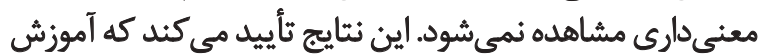

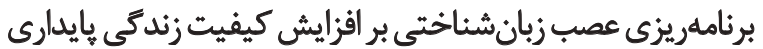

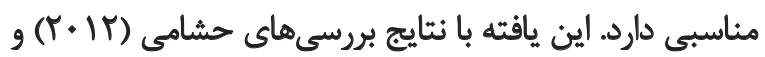

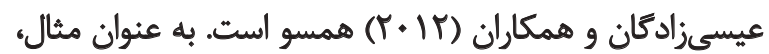

جدول r. آزمون t همبسته براي مقايسه تغييرات ميانكين نمرات اميد كروه آزمايش برنامهريزى عصب زبانشئاختى در مرحله بيكيرى (·r=r)

\begin{tabular}{|c|c|c|c|c|c|c|}
\hline سطح معنادارى & درجه آزادى & t & خطاى استاندارد & مياتئين (انحراف استاندارد) & مرحله & متغير \\
\hline.$/ \Delta P$ & 19 & $-r / \& \Delta$. & $1 / 19$ & $-r / T \otimes(\Delta / M)$ & ييكيرى & 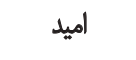 \\
\hline.$/ . q \varepsilon$ & 19 & -IVAT & . Iar & $-1 / 1+(Y / \Lambda \cdot)$ & ييكيرى & قدرت ارادها \\
\hline .1 .81 & 19 & -1/94r & $.1 . \Delta q$ & $-1 / 1 \Delta(Y / \& E)$ & ييكيرى & قدرت راهيابي \\
\hline
\end{tabular}




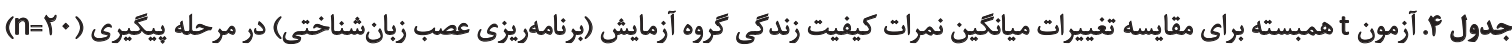

\begin{tabular}{|c|c|c|c|c|c|c|}
\hline سطع معنادارى & ورجه آزازي & 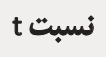 & خطاي استائدارد & ميانئين (انحراف استائدارد) & مرحله & متغير \\
\hline $.1 \cdot 18$ & 19 & $-T / \varepsilon+F$ & $\cdot M$ & $-+/ \Delta \Delta(\cdot / 94)$ & ييكيرى & كيفيت زندكى \\
\hline.$/ 4 \wedge$. & 19 & $\cdot M T I$ & .199 & $\cdot / \Delta \cdot(\mu / 1 \cdot)$ & ييكيرى & رفاه فيزيكى \\
\hline.$/ M M$ & 19 & $1 / \pi r m$ & / & $+/ \Delta \Delta(1 / 94)$ & ييكيرى & رفاه روانى \\
\hline.$/ 194$ & 19 & $-1 / \pi T V$ & . $10 \mathrm{r}$ & $-* / N \cdot\left(\cdot / M^{q}\right)$ & ييكيرى & احساسات و عواطف \\
\hline.$/ 199$ & 19 & $-1 / M T H$ &.$/ 4 \wedge$ & $-+/ \varnothing \Delta(Y / \backslash A)$ & ييكييرى & درى الزّ خُود \\
\hline.$/ T \Delta 1$ & 19 & $-1 / M A r$ &.$/ 4 \Lambda$ & $-+/ f \Delta(1 / N+)$ & ييكيرى & خودمختارى \\
\hline.$/ 1$ & 19 & $-1 / e n e$ &.$/ 1 V$ & $-\cdot / \pi \cdot(\cdot / \lambda \cdot)$ & بيكيرى & روابط واللدين \\
\hline $.1 .9 \vee$ & 19 & IMEA &.$/ 4 V$ & $.180(1 / 89)$ & نيكيرى & حمايت اجتماعي \\
\hline $1 / \ldots$ & 19 & 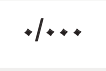 &.$/ 0 F$ &.$\cdot(t / M T)$ & ييكيرى & هحيط ملرسه \\
\hline.$/ \Delta W$ & 19 &.$- / A Q V$ & $\cdot 1 \cdot 1$ & $-\cdot 1 \cdot \Delta(\cdot / \% q)$ & ييكيرى & ليذّيرش اجتماعى \\
\hline.$/ 1 \notin V$ & 19 & -I/RTY &.$/ \pi F$ & $-\cdot / r \Delta(1 / \cdot 1)$ & ييكيرى & منابع مالى \\
\hline
\end{tabular}

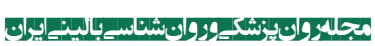

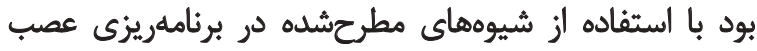

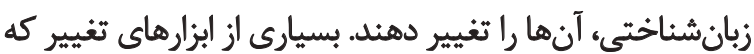

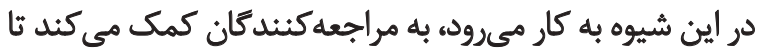

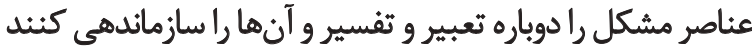

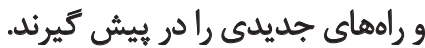

نظامهاى بازنمايي در برنامهريزى عصب زبانشناختي به فرد

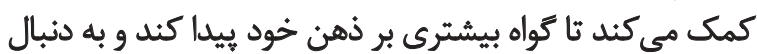

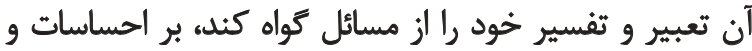

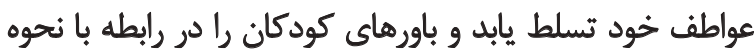

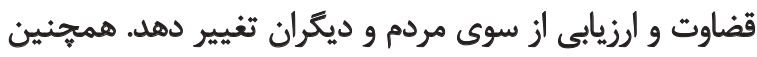

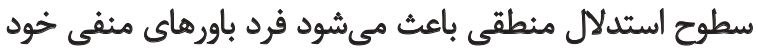

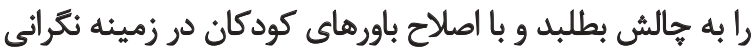

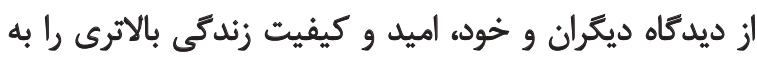

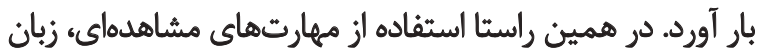

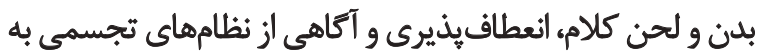

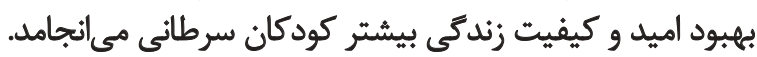

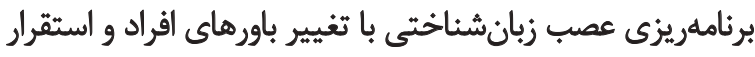

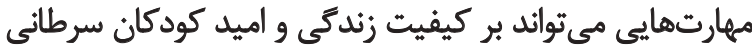
اثرات هايدارى داشتثله باشد.

\section{نتيجليَّيرى}

با توجه به يافتههاى بثروهش حاضر و با در نظر كرفتن نثايج

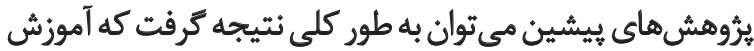

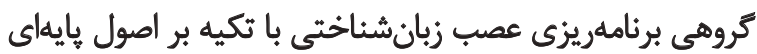

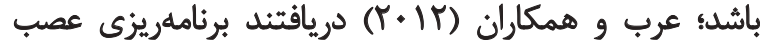

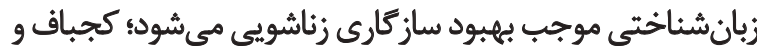

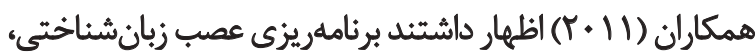
ساز كارى زناشويى را ارتقا بخشيده است.

ثب يثروهش حاضر با هدف بررسى اثربخشى آموزش كروهى

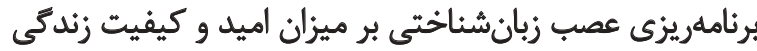

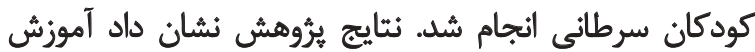

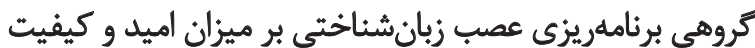

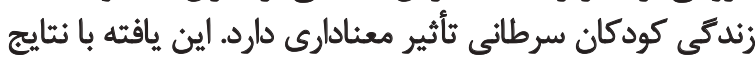

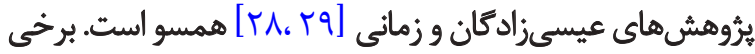

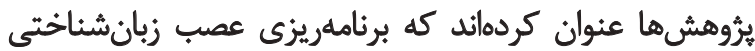

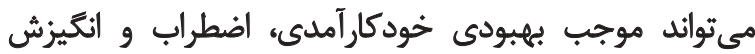

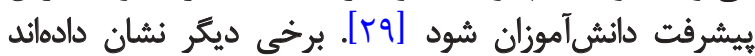

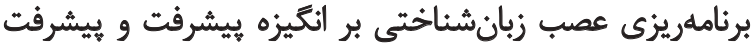
تحصيلى دانش آموزان مؤثر است [ـــــ از آنجايى كه روش برنامهريزى عصب زبانشناختى و درمان

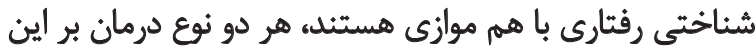

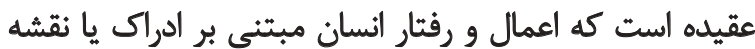

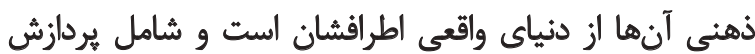

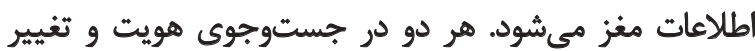

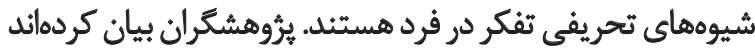

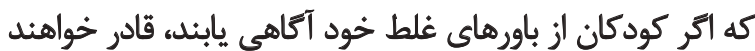


و تكنيكهاى خود با تأثير كذارى بر سطح ارتباط فرد با ديكران

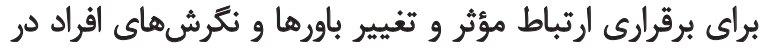

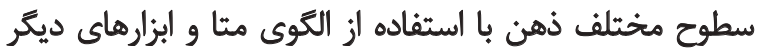

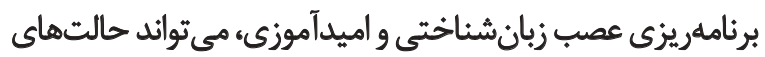
سلامتى كودكان سرطانى راكشف و الكوسازى كند.

با استفاده از برنامهريزى عصب زبانشناختى، كودكان سرطانى

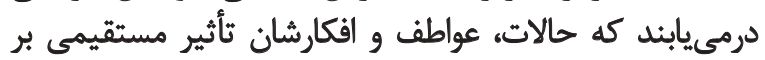

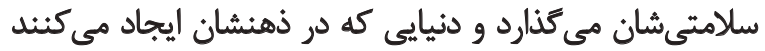

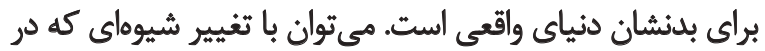

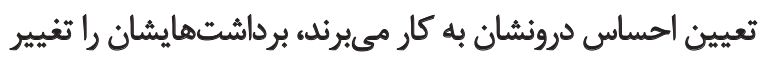

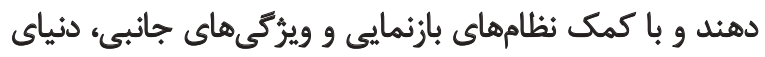

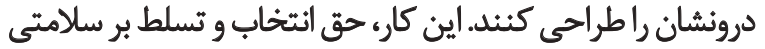

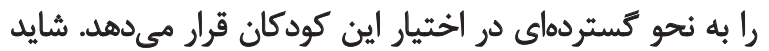

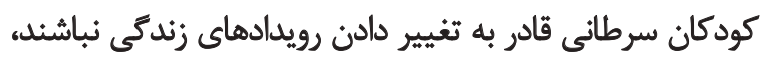

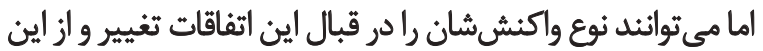

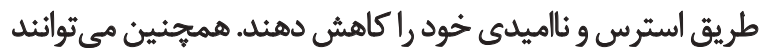

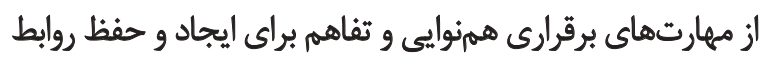

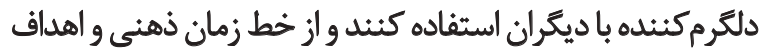

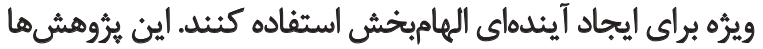

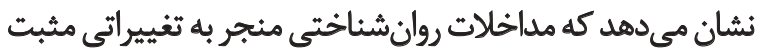
و افزايش اميد و كيفيت زندگى كودكان سرطانى مئى مشود.

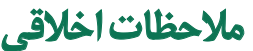

بيروى از اصول اخلاق يُوهش

در اين يثوهش فرم رعايت نكات اخلاقى توسط درمانجو تكميل و توسط درمانكر رعايت شده است.

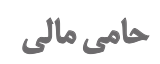

اين مقاله از باياننامه كارشناسى ارشد خانم ساناز آقاخانى در

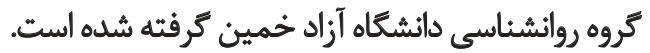

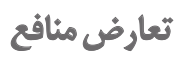

بنابر اظهار نظر نويسندكان اين مقاله متعارض منافع ندارد. 


\section{References}

[1] Eiser C. Children with cancer: The quality of life. Journal of the Canadian Academy of Child and Adolescent Psychiatry. 2008; 17(3):161-2. [PMCID]

[2] Robinson KE, Gerhardt CA, Vannatta K, Noll RB. Parent and family factors associated with child adjustment to pediatric cancer. Journal of Pediatric Psychology. 2007; 32(4):400-10. [DOI: 10.1093/jpepsy/jsl038] [PMID]

[3] Loprinzi CE, Prasad K, Schroeder DR, Sood A. Stress Management and Resilience Training (SMART) program to decrease stress and enhance resilience among breast cancer survivors: A pilot randomized clinical trial. Clinical Breast Cancer. 2011; 11(6):364-8. [DOI:10.1186/1472-6882-12-S1-P211] [PMID]

[4] Hossein Qomi T, Salimi H. The effectiveness of resuscitation training on mothers' stress with cancer children at Imam Khomeini Hospital in Tehran. Health Psychology. 2013; 1(4):97-109.

[5] Tsui HH, Meei SL, Tsung ST, Ghia CL. The relationhip of pain, uncertainy, and hope in Taiwaneslung cancer patients. Journal of Pain and Symptom Management. 2003; 26(3):835-42 [DOI:10.1016/S0885-3924(03)00257-4] [PMID]

[6] Medina-Franco H, Abarca-Pérez L, Cortés-Gonzlez R, Soto-Germes S, Ulloa JA, Uribe N. [Fine needle aspiration biopsy of breast lesions: institutional experience (Spanish)]. Clinical Research Journal. 2005; 57(3):394-8. [PMID]

[7] Dilts R, Delozeier JA. Encyclopedia of systemic neuro linguistic programming and NLP new coding. California: Scotts valley; 2000

[8] Noori Daloii MR, Fazilaty H, Tabrizi M. Cancer metastasis, genetic and microenvironmental factors of distant tissue: A review article. Tehran University Medical Journal. 2013; 70(11):671-83.

[9] Savar Delavr M, Vneur JA. [Fundamentals of neurolinguistic programming: NLP in cognitive perspective (Persian)]. Tehran: Arjmand Pub; 2008

[10] Whitman GJ, Tracy JL, Adejolu M, Krishnamurthy S, Sheppard D. Lymph node sonography. Journal of Clinical Ultrasound. 2011; 6(3):369-80. [DOI:10.1016/j.cult.2011.05.005]

[11] Heshami S. [Comparison of the effect of Neuro-Linguistics Programming (NLP) and group cognitive therapy on depressive women and men in Farabi Hospital of Kermanshah (Persian)] [MA thesis]. Tehran: Payame Noor University; 2012.

[12] Isazadegan A, Dastori R, Abdoli sultan Ahmadi G. The effectiveness of Neurolinguistic Programming (NLP) strategies on self-efficacy, anexity and achievement motivation among boy students. Quartery Journal of Phycological Studies. 2013; 8(4):7394. [DOI: 10.22051/PSY.2013.1731]

[13] Shoa'e Kazemi M, Momeni Javid M. [Relationship between quality of life \& hope in Breast cancer patients after surgery (Persian)]. Iranian Journal of Breast Diseases. 2009; 2(3, 4):20-7.

[14] Heidari AR, Jafari F. [Comparison of quality of life, social support and general health of people infected with AIDS with healthy people in Ahvaz (Persian)]. New Findings in Psychology (Journal of Social Psycology). 2008; 2(7):47-60

[15] Taylor SE, Welch WT, Kim HS, Sherman DK. Cultural differences in the impact of social support on psychological and bio- logical stress responses. Psychological Science. 2007; 18(9):831-7. [DOI:10.1111/j.1467-9280.2007.01987.x] [PMID]

[16] Suarez L, Ramirez AG, Villarreal R, Marti J, Mcalister A, Talavera GA, et al. Social networks and cancer screening in four U.S. Hispanic groups. American Journal of Preventive Medicine. 2000; 19(1):47-52. [DOI:10.1016/S0749-3797(00)00155-0]

[17] McDermott I, O'Connor J. NLP and health: Using enhance your health and well-being. Ontario: Thorsons; 1996.

[18] Bahari F. [The fundamentals of hope and hope therapy: A guide to hope creation (Persian)]. Tehran: Danzhe; 2011.

[19] Keenaghan C, Kilroe J. A study on the quality of life tool Kidscreen for children and adolescents in Ireland: Results of the Kidscreen national survey 2005, health service executive and the Kidscreen group Europe. Dublin: Office of the Minister for Children and Young People/Department of Health and Children; 2008.

[20] Karimi Eyvanaki M. [Standardization of children's hope scale in the sphere of life (Persian)] [MA thesis]. Arak: Islamic Azad University; 2012.

[21] Golzarie M. [Validation of a Schneider hope scale (Persian) [Unpublished]. Tehran: Allameh Tabatabai University; 2007.

[22] Lopez SJ, snyder CR. Positive psychological assessment: A handbook of models and measures. Washington: American Psychological Association; 2008

[23] Zeighami M, Hoshmand Sh, Kooshyar MM. Esmaeili H. Quality of life in cancer patients undergoing chemotherapy. Scientific Journal of Hamadan Nursing \& Midwifery Faculty. 2008; 16(1):5-15.

[24] Karimidarmani HR. [Rehabilitation of specific groups (with emphasis on social services) (Persian)]. Tehran: Roshd; 2004.

[25] Eliott J, Olver I. The discursive properties of "Hope": A qualitative analysis of cancer patients' speech. Qualitaive Health Research. 2004; 12(2):173-93.

[26] Oconor J, Simor J. Neurolinguistic Programming: NLP [M. Gharache Daghi, Persian trans]. Tehran: Alborz Pub; 2008.

[27] Arab Baferani HR, Abedi A, Behrooz B, Naghavi M, Ashrafabadi M. [The effect of teaching neuro-linguistic programming on the couples' marital adaptation referring to consultation centers of isfahan (Persian)]. Journal of Modern Psychological Researches. 2012; 7(28):141-57.

[28] Issazadegan A, Dastorie R, Abdoli Soltanahmadi J. The effectiveness of Neurolinguistic Programming (NLP) strategies on self-efficacy, anexity and motivation of pre-university school students. Quarterly Journal of Psychological Studies. 2013; 8(4):94-73. [DOI: 10.22051/PSY.2013.1731]

[29] Zamini S, Hoseini Nasab SD, Hashemi T. [The impact of NLP training strategies on achievement motivation and academic achievement among female students (Persian)]. Journal of Research in Psychological Health. 2007; 1(3):51-9.

[30] Hosseini A. [Basic study of Islamic psychology principles (Persian)]. Tehran: Islamic Culture Publishing Office; 2008. 
